\title{
Impact of Anthropogenic Activity on Community Structure and Function of Microbiomes in Polluted Stretches of River Yamuna at New Delhi, India: Insights From Shotgun Metagenomics
}

\section{Pranaya Kumar Parida}

Central Inland Fisheries Research Institute

Bijay Kumar Behera ( $\sim$ beherabk18@yahoo.co.in )

Central Inland Fisheries Research Institute https://orcid.org/0000-0003-4960-9768

Budheswar Dehury

Central Inland Fisheries Research Institute

Ajaya Kumar Rout

Central Inland Fisheries Research Institute

Dhruba Jyoti Sarkar

Central Inland Fisheries Research Institute

Anil Rai

Indian Agricultural Statistics Research Institute

Basnata Kumar Das

Central Inland Fisheries Research Institute

Trilochan Mohapatra

Indian Council of Agricultural Research

\section{Research Article}

Keywords: River Yamuna, Metagenomic Analysis, Microbial communities, Sediment, sewage waste

Posted Date: February 15th, 2022

DOI: https://doi.org/10.21203/rs.3.rs-1282532/v1

License: (c) (i) This work is licensed under a Creative Commons Attribution 4.0 International License. Read Full License 


\section{Abstract}

The large population residing in the northern region of India surrounding Delhi mostly depends on water of River Yamuna, a tributary of mighty Ganga for agriculture, drinking and various religious activities. However, continuous anthropogenic activities mostly due to pollution mediated by rapid urbanization and industrialization has profoundly affected river microflora and their function thus its health. In this study, potential of whole genome metagenomics was exploited to unravel the novel consortia of microbiome and their functional potential in the polluted sediments of the river at Delhi. Analysis of high-quality metagenome data from Illumina NextSeq500 revealed substantial differences in composition of microbiota at different sites dominated by Proteobacteria, Bacteroidetes, Firmicutes, Actinobacteria and Chloroflexi phyla. The presence of highly dominant anaerobic bacteria like, Dechloromonas aromatica (benzene reducing and denitrifying), Rhodopseudomonas palustris (organic matter reducing), Syntrophus aciditrophicus (fatty acid reducing), and Syntrophobacter fumaroxidans (sulfate reducing) in the polluted river Yamuna signifies the impact of unchecked pollution in declining health of the river ecosystem. A decline in abundance of phages were also noticed along the downstream of river Yamuna. Mining of mycobiome reads uncovered plethora of fungal communities (i.e., Nakaseomyces, Aspergillus, Schizosaccharomyces, and Lodderomyces) in the polluted stretches due to the availability of higher organic carbon and total nitrogen (\%) could be decoded as promising bioindicators of river trophic status. Pathway analysis through KEGG revealed higher abundance of genes involved in energy metabolism (nitrogen and sulphur), methane metabolism, degradation of xenobiotics (Nitrotoluene, Benzoate and Atrazine), two-component system (atoB, cus $A$ and sil $A$ ) and membrane transport (ABC transporters). Catalase peroxidase and 4-hydroxybenzoate 3-monooxygenase were the most abundant pollution degrading enzymes in polluted sites of river Yamuna. Overall, our results provide crucial insights into microbial dynamics and their function in response to high pollution and could be insightful to the ongoing remediation strategies to clean river Yamuna.

\section{Introduction}

River Yamuna is one of the major rivers of Ganges River systems of India, running from Yamunetri glacier to Prayagraj where it meets with river Ganga at Triveni Sangam. The river is having its own importance in Indian Mythology and nearly 57 million people depend on its water and considered as a holy river (Jain et al., 2007). Around 97 million gallon of water flows in the river and out of which 4 million gallon is consumed every year (CWC, 2011). From ancient times, human civilization is dependent on river for agriculture and household purposes. However, nowadays these rivers are being polluted day by day due to various anthropogenic activities and impeding the health of the Ecosystem. The Central Pollution Control Board of India has reported that, Yamuna is heavily suffering for a long time from pollution such as unprocessed municipal and industrial sewages, harmful pesticides used for agriculture, medi-waste, etc (CPCB, 2018).

The city of Delhi, which is in the bank of river Yamuna is profoundly populated and totally depends on river Yamuna for its water requirements. In the bank of river Yamuna, numerous industries are operating, 
therefore, it receives gallons of domestic and industrial sewage in Delhi stretch covering more than 100 $\mathrm{Kms}$ (Muthaiyah, 2020). Hence it is essential to understand the level of pollutants in the Yamuna River system and also the in-built buffering capacity of the river to remediate these pollutants. It is reported extensively that the native microbial population through various microbial pathways are capable to degrade or transform pollutants thus lowering the level of pollution (Abatenh et al., 2017). It is reported that the sediment of river harbours a lot of micro-organisms having various helpful properties like degradation of organic materials, nitrogen cycling, heavy metal degradation and many more beneficial properties (Himmelberg et al., 2018; Wang et al., 2021; Yan et al., 2019). However, it is very much difficult to understand and generate knowledge on the various microbial communities and their interrelationship present in the aquatic system through traditional microbiological techniques. Metagenomics analysis of the river sediment through Next Generation Sequencing (NGS) technique plays a vital role in revealing the taxonomic classification of unculturable microbiota and important microbial pathways in delineating the major bioremediation process of the pollutants (Alves et al., 2018; Gibbons et al., 2014; Reddy and Dubey, 2019a).

The contemporary advancement of science has potentially fabricated to overcome the barriers of culturebased techniques and set a fair view of microbial diversity via phylogenetics and functional genomics study (Simon and Daniel, 2009). Shotgun metagenomics approaches has been used for identification of microbes for biodegradation of aromatic waste from the sediments of San Jacinto River (lyer and Damania, 2020) and xenobiotic biodegradation microbes from mangrove sediments (Cabral et al., 2019).

Further, the metagenomics studies and bioinformatics analysis have helped the researchers to identify the beneficial microbes from the river sediments for the industrial usage. Beneficial and bioremediation bacteria have been identified by our group from the metagenomic analysis of sediment samples of river Ganga Behera et al., 2020a; Behera et al., 2020b). Using sediment metagenome data from river Yamuna, a recent study has identified several classes of antimicrobial resistance genes (AMR) (Das et al., 2020a). Moreover, over the last five years several research groups have identified the microbial communities and their functional properties from different river sediments through metagenomic approach (Abia et al., 2018; Chen et al., 2019; Chu et al., 2018; Mittal et al., 2019a; Reddy and Dubey, 2019b).

It has been suggested that, microbes are important for the ecosystem and biogeochemical cycle. River Yamuna in the polluted stretches the microbes thriving with different types of pollutants (domestic, industrial and other pollutants) must be having genes for various pollutant degradation like organic matter, heavy metal, xenobiotic degradation etc. Owing to the importance of river sediments in maintenance of ecological health of river, the present study aimed at understanding the diverse microbial community structure (bacteria, archaea, fungi and virus/phages) and their imperative function through whole genome metagenomics approach from different polluted stretches of river Yamuna at Delhi. Further, attempts were also made to investigate the correlation between microbiome composition and function with the water and sedimental properties. The results of our study provide an extensive information into the microbiome, genes/enzymes content, and their functional pathways, active in highly polluted river sediment of river. 


\section{Materials And Methods}

\section{Selection of study site and collection of soil sample}

In this study, three polluted sites of river Yamuna in Delhi viz. Wazirabad (sample-1), Okhla (sample-2), Faizpur (sample-3) were selected for collection of sediment and water samples (Fig. S1). Approximately, $500 \mathrm{~g}$ sediment samples were collected at a depth of $20 \mathrm{~cm}$ from three different sampling locations of Delhi stretch of River Yamuna, India. The sampling locations were Wazirabad (Sample-1; $28^{\circ} 42.39^{\prime \prime} \mathrm{N}$

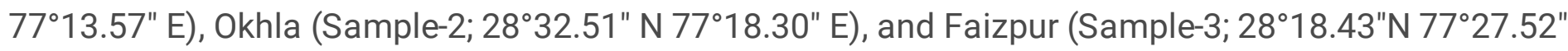
E). From each sampling location, we collected sediment samples from five random sites and pooled together. The collected sediment samples are kept in single sterile plastic container at $4^{\circ} \mathrm{C}$ while transporting and stored in the laboratory at $-80^{\circ} \mathrm{C}$.

\section{Analysis of physio-chemical parameters}

The river water samples collected from three sites of Delhi stretch of River Yamuna for dissolved oxygen (DO), total dissolved solid (TDS), specific conductivity $(\mu \mathrm{S} / \mathrm{cm})$, salinity $(\%)$, chemical oxygen demand (COD), biological oxygen demand (BOD) and $\mathrm{pH}$, were analysed as per the standard methods of APHA (APHA AWWA, 2012a). The sediment samples collected from three sites for available phosphate, organic carbon, $\mathrm{pH}$, total nitrogen, and specific conductivity were also analysed as per APHA standard methods (APHA AWWA, 2012b).

\section{Isolation and quantification of genomic DNA}

Nucleospin ${ }^{\circledR}$ Soil Kit was used to isolate metagenomic DNA from the collected sediment as per the manufacturer's protocol. DNA quality check was performed on $0.8 \%$ agarose gel which was run for 30 minutes at $110 \mathrm{~V}$ and absorbance (260/280 ratio) in Nanodrop-2000 using $1 \mu \mathrm{l}$ sample.

\section{Illumina NextSeq 2x150 PE library preparation, quality check, and tape station profiling}

Using IlluminaTruSeq Nano DNA HT Library preparation kit, we prepared paired-end sequencing libraries for each sample. 200ng of gDNA was fragmented by Covaris to generate a mean fragment distribution of $350 \mathrm{bp}$. The ligated products were then purified using AMpureXP beads. PCR amplification for the sizeselected products was performed as described in the kit protocol. Analysis of the PCR enriched libraries was performed using High sensitivity D1000 Screen tape in 4200 Tape Station system (Agilent Technologies) as per manufacturer protocol. The PE libraries were prepared to employ TruSeq Nano DNA Library Preparation Kit. The mean of the library fragment size distributions is $480 \mathrm{bp}$, $469 \mathrm{bp}$ and $472 \mathrm{bp}$ for Sample-1, Sample-2 and Sample-3, respectively.

\section{Next-Generation Sequencing and data submission}

After Qubit concentration retrieval for different libraries and procured mean peak size from Agilent Tape Station profile, using the PE Illumina library on NextSeq 500, clustering and sequencing was performed. 
All sequence data generated in this study were submitted to the NCBI Sequence Read Archive (SRA) under Accession Numbers (SRS4592195, SRS4592470 and SRS4600533).

\section{Quality control, De-novo Assembly of Metagenome and Gene Prediction}

Trimmomatic v0.35 was used to remove the adapter sequences, ambiguous reads (reads with unknown nucleotides " $\mathrm{N}$ " larger than $5 \%$ ), and low-quality sequences (reads with more than $10 \%$ quality threshold value (QV) $<20$ Phred score) from the sequenced raw data to obtain high-quality clean reads. After trimming, a minimum length of $100 \mathrm{nt}$ (nucleotide) was applied for the identification of different species in the sediment metagenome. Filtered high-quality metagenomic reads of all the three samples were assembled into Scaffolds using the CLC Genomics Workbench version 8.5.1. Genes were predicted from the assembled scaffolds of high throughput reads using Prodigal with default parameters.

\section{Gene Annotation}

Annotation was made for the predicted genes from sediment metagenomic data. BLASTx was used to perform the functional annotation of the predicted genes from all the three samples.

\section{Taxonomical Analysis}

Taxonomical classification of the Sediment samples was computed by MEGAN (Huson et al., 2007) using LCA algorithm based on a BLASTx comparison by taking the predicted genes against the NCBI-NR database. The hierarchical classification of microbes has been performed at different levels like phylum, class, order, family, genus, and species. The predicted genes with length less than $300 \mathrm{bp}$ were not included in the analysis. For phage identification, MG-RAST web server (Meyer et al., 2008) was used, with default setting of $60 \%$ similarity, sequence coverage of 15 and a maximum cut-off e-value of $10^{-}$ 5 . The scaffold files were used as input file and the virus were identified up to species level taking a cutoff hit value of 20 for the samples.

\section{Functional analysis of metagenomes}

SEED(Overbeek et al., 2005a) is an interface for batch processing of amplicon sequencing data which facilitates quality trimming, clustering of microbial community statistics along functional role assignment. SEED uses the subsystem approach, where all of the genes implemented in the subsystem are scrutinized by an expert in that subsystem (Overbeek et al., 2005b). SEED analysis was carried out for the three metagenomic data of sediment samples for functional analysis. Functional prediction was also made by using Cluster of Ortholog (COG) database (Tatusov et al., 2000) to cluster protein functions using the BLASTx annotation of the genes.

To predict functional pathways, KEGG (Kyoto Encyclopaedia of Genes and Genomes) analysis was performed for the significant genes derived from the sediment metagenome using the best hit with a known reference sequence (Kanehisa et al., 2017). The KEGG classification is characterized by a rooted tree (with approximately 13000 nodes), where leaves represent different pathways. Functree2 software 
(Darzi et al., 2019) was used to plot the functional tree plot using the KO values extracted for three samples using MG-RAST (Meyer et al., 2008) and MGNIFY (Mitchell et al., 2020). To screen important pollutant degrading enzymes (PDEs) from annotated genes, we used DIAMOND (Buchfink et al., 2015) with the stringent search criteria "diamond blastx -e 0.00001 -id 60 -very-sensitive" against database of RemeDB (Sankara Subramanian et al., 2020).

\section{Statistical analysis}

The multi-variate statistical tool principal component analysis (PCA) was used to quantify the relationship between relative abundance of microbes, pathway and Phages with water and sedimental properties using JMP Pro 10 (JMP ${ }^{\circledR}$, Version 10. SAS Institute Inc., Cary, NC, 1989-2019) after standardization of the estimated data. For PCA, we generated biplot of the first two principal components (PC1 vs. PC2) and scatter plot matrix for correlation analysis.

\section{Results}

\section{Assessment sediment and water quality}

Sediment samples were collected from three locations (Wazirabad, Okhla and Faizpur) of Delhi stretch of the river Yamuna. The water and sediment quality parameters are summarized in the Table $\mathbf{S 1}$. It can be clearly observed from Table S1 that, the DO is very less in the flowing water along the polluted stretch. Quantitatively, sampling point- 1 had less amount of DO as compared to other two sampling points. In contrast to DO, sampling point-2 had very high COD than the other two points. While in case of BOD, all sampling points had higher BOD values signify requirement of more oxygen, which is scanty for oxygendemanding species to feed on, and implies inferior water quality.

\section{Metagenome data and statistics}

High throughput next-generation sequencing was performed for each sediment sample to identify the microbial diversity. All three samples passed the quality check via quantification of DNA using Qubit/NanoDrop. The statistics of high-quality reads for each sediment sample is presented in Table S2. After removing the adapter and low-quality sequences from the raw data high quality reads were retained for sediment samples (sample-1, sample-2 and sample-3, respectively) (Table S2). The high quality paired-end reads were then used for referenced based read mapping.

\section{Denovo assembly, gene prediction and Annotation}

The filtered high-quality reads of all three samples were assembled into Scaffolds using CLC Genomics Workbench. The statistics obtained from gene prediction from the assembled scaffolds using Prodigal with default parameters are summarized in (Table S2). Performing BLASTx search for homologous sequences against a non-redundant (NR) database with filtered sediment metagenome revealed that (taking only $>300$ bp gene length), out of total 1,096,541, 1,661,983 and 1,902,192 numbers of genes, 
$1,063,628,1,308,835$ and 1,032,192 numbers of genes were functionally annotated for Wazirabad (Sample-1), Okhla (Sample-2) and Faizpur (Sample-3) respectively.

\section{Taxonomical profile of sediment microbiome}

All approaches of taxonomical classification study confirmed the presence of large numbers of bacterial communities (Table S3). Comparative domain level study showed that, the occurrence of bacteria was higher in Faizpur sediment as compared to two other sediment samples, whereas, Okhla sediment had a higher abundance of Archaea, Eukaryotes than other samples.

\section{Abundance of Bacteria, Archaea and Fungi}

The occurrence of microbial domains was studied at phylum and class level for all three annotated metagenomes. High throughput sequencing and bioinformatics analysis revealed the presence of a major bacterial phylum in all sampling sites, Proteobacteria (52\% of total bacterial reads) (Fig.1A). Among Proteobacteria, more than 97\% were constituted by Alphaprotepobacteria, Betaproetobacteria, Deltaproteobacteria and Gamma proteobacteria (Fig. 1B). The occurrence of other bacteria at the phylum level at three sampling sites in the Delhi stretch of river Yamuna were Firmicutes, Bacteroidetes, Actinobacteria, Chloroflexi, Verrumicrobia, Cyanobacteria and Acidobacteria etc. (Fig. 1A). At species level Dechloromonas aromatica, Rhodopseudomonas palustris, Syntrophus aciditrophicus and Syntrophobacter fumaroxidans were the major species found in metagenomes of river sediment (Table S4).

Looking at the archaeal diversity, Euryarchaeota were dominating at phylum level in all of the three samples and contributes to more than $92 \%$ in all the samples. Methanobacteriaceae,

Methanosarcinaceae, Methanospirillaceae are the major abundant families in all the samples. Methano regulaboonei, Methanoculleus marisnigri, Methanosaeta thermophila and Methanospirillum hungatei are major abundant archaeal species in all the samples (Table S5).

Among the eukaryotes, taxonomic assignments in revealed a total of 21 phyla in each sample. The predominant phylum among fungi was Ascomycota in all the samples with a relative abundance of $14.31 \%, 16.31 \%$, and $16.53 \%$ corresponding to sample- 1 , sample-2 and sample-3 respectively. Other phylums including Basidiomycota, Blastocladiomycota and Chytridiomycota were also accounted for $\sim 3 \%$ in three metagenomes (Supporting Info). A higher relative abundance of family Trichocomaceae (24.72\%), Nectriaceae (8.93\%), Saccharomycetaceae (8.92\%), Schizosaccharomycetaceae (5.02\%) Tremellaceae (4.38\%), and Sordariaceae (4.39\%) dominated all the samples. At species level a number of unique fungal species i.e., Neosartorya fumigate, Gibberellazeae, Cryptococcus neoformans, Neurospora crassa, Schizosaccharomyces pombe, Ustilago maydis, and Yarrowialipolytica were identified as dominant mycobiomes in three metagenome data

\section{Diversity in virus including phage and their abundance}


Based on the MG-RAST analysis, the various phages (up to species level) were identified from the metagenome sequence data. Among the phages (Virus) at family level, Myoviridae, Podoviridae, and Siphoviridae were the major groups in all the three samples (Table S6). Myoviridae constituted 33\%, 31\% and $39 \%$ in sample-1, sample-2 and sample-3, respectively. Similarly, Podoviridae attributed to $25 \%, 21 \%$ and $23 \%$; and Siphoviridae contributed $33 \%, 36 \%$ and $23 \%$ in sample-1, sample-2 and sample-3, respectively. While at genus level, T-4 like virus, Bpp-1 like virus and N-4 like virus were dominating in all the samples (Table S6). Most interestingly at species level, Bordetella phage BPP-1 was the most dominating followed by Pseudomonas phage F116, Prochlorococcus phage P-SSM2 and Rhizobium phage 16-3 in all the three sediment samples. The phages were more diverse in the sample-1 and sample2 as compared to sample-3 (Fig. 2).

\section{Functional annotation of genes}

SEED functional classification showed that a total of $384,390,477,961$ and 410,992 numbers of genes were assigned to three sediment samples of sample-1, sample-2 and sample-3, respectively (Fig. 3). SEED analysis depicted that several types of functional genes were present in these microbiome data, of which genes associated with "carbohydrate metabolism" (i.e., $10.45 \%, 11.22 \%$ and $12.21 \%$ for sample- 1 , sample-2 and sample-3, respectively), and "amino acids and derivatives metabolism" (9\%, 8.6\% and $8.7 \%)$ represents the major classes under SEED category. Remarkably, genes associated with virulence, disease, and defence were also observed in all samples. All total, $2.66 \%, 2.44 \%$ and $2.38 \%$ of genes present in the sediment sample-1, sample-2 and sample-3, respectively responsible for stress response. It was also revealed that more than $0.8 \%$ of the genes to be involved in the sulphur metabolism process. The doughnut plot (Fig. 3A) represents the proportion of genes assigned directly to the different SEED categories.

A total $361,684,437,640$ and 376,260 numbers of genes were assigned with different functional categories using COG for sample-1, sample-2 and sample-3 respectively. Genes associated with "general function", "energy production and conversion", "amino acid transport and metabolism", "translation, ribosomal structure and biogenesis", "carbohydrate transport and metabolism" and "replication, recombination and repair" were highly abundant than other functional categories at level-2 (Table S7). COG analysis also revealed that more than $2.68 \%$ of the genes are involved in defence mechanism in all the samples. Different COG categories are shown in Doughnut chart (Fig. 3B).

Similarly, 316,633, 390,691 and 344,375 numbers of genes were assigned to sediment samples (sample1, sample-2 and sample-3, respectively) using KEGG functional annotation. KEGG functional classification showed that $59 \%$ of genes were associated with "metabolism", $18 \%$ of genes were responsible for "genetic information processing", $15 \%$ of the gene were involved in "environmental information processing" at level-1. Under "metabolism", 3006(0.94\%), 2503(0.64\%) and 2156(0.62\%) number of genes were involved in xenobiotics biodegradation and metabolism at level-2 (Table S8, Table S9). The functional profiling of genes assigned through "KO" were enumerated using FuncTree2 to exhibit functional hierarchies at different levels (KEGG BRITE 1, BRITE 2, Pathway, and KO) is shown in in Fig. 4. 
The relative abundance of major pathways using KEGG at level 3 displayed 234 pathways of which ABC transporters (ko02010), aminoacyl-tRNA biosynthesis (ko00970) and two-component system (ko02020) contributed to $7.82 \%, 5.14 \%$, and $4.26 \%$ of total detected pathways respectively (Supporting Info). The higher abundance of functional genes involved in $A B C$ transporters (involved in transportation within membrane) and two-component system (involved in signal transduction) in all the samples indicates their functional significance in membrane transport and signal transduction. $A B C$ transporter genes (potA, modA, ftsE, modB, pstA) (Fig. 5) had an increased abundance in all samples where members of phylum Proteobacteria (Bradyrhizobiaceae, Comamonadaceae, Rhizobiaceae, Rhodocyclaceae, Xanthobacteraceae, Rhodobacteraceae), Actinobacteria (Bifidobacteriaceae) and Firmicutes (Clostridiaceae) belonging contributed $58 \%, 13.6 \%$ and $6.9 \%$ respectively. While, in case of two-way component system, Proteobacteria belonging to family Rhodocyclaceae, Comamonadaceae, Geobacteraceae, Bradyrhizobiaceae, Pseudomonadaceae, Rhodobacteraceae, Desulfobacteraceae, Myxococcaceae, and Burkholderiaceae contribute significantly (Supporting Info) with their functional machinery to linking microbial physiology to the environment and thus has a major role in biogeochemical cycles.

Pollution due to highly abundant xenobiotic compounds in Indian riverine systems including Yamuna, we made an attempt to inspect genes accountable degradation of such compounds from the polluted microbiome. "Xenobiotic biodegradation and metabolism" represent one of the major pathways involved in biotransformation of such complex compounds. Close inspection revealed several genes (mostly from Proteobacteria and Actinobacteria) were involved important sub-KO pathways responsible for nitrotoluene, benzoate, atrazine, caprolactam, xylene, bisphenol and steroids etc (Fig. S2A).

Higher abundance of the xenobiotic degradation reads was filtered by the bacterial family (Fig. S2B) Bradyrhizobiaceae, Burkholderiaceae, Rhodocyclaceae and Comamonadaceae (Supporting Info) The detailed information on number of genes/enzymes i.e., carboxymethylenebutenolidase, 2-haloacid dehalogenase, phenol 2-monooxygenase degradation of chlorocyclohexane and chlorobenzene (ko00361); 4-carboxymuconolactone decarboxylase benzoate-CoA ligase involved in benzoate degradation (ko00362); hydrogenase, N-ethylmaleimide reductase involved degradation of nitrotoluene degradation (ko00633); and carboxylesterase (1 and 2) involved in metabolism of drugs (ko00983) are illustrated in Table S10 and Fig. S3. These close observations from pathway analysis reflects those microbes thrive in polluted segments of river Yamuna are capable degrading xenobiotic compounds which may plausibly distress the efficacy of drugs with reverence to human health.

Further mapping of $\mathrm{KO}$ revealed more than $0.8 \%$ of the total genes annotated in KEGG pathways were responsible for "Methane metabolism", $0.29 \%$ in "Sulfur metabolism", $0.71 \%$ in "Nitrogen metabolism" (Table S9).

\section{Mining of pollution degrading enzymes}

The polluted sediment metagenomic reads were mapped against the dataset of genes/enzymes of RemeDB database to retrieve details of genes involved in PDEs. Among the major PDEs, Catalase- 
peroxidase, Catalase, p-hydroxybenzoate hydroxylase, 4-hydroxybenzoate 3-monooxygenase, Methylaccepting chemotaxis protein III, Phenol 2-monooxygenase and Toluene-4-monooxygenase were predominant in polluted river Yamuna. Presence of Peroxidases (involved in degradation of dyes and xenobiotics), 4-hydroxybenzoate monooxygenase and Biphenyl 2,3-dioxygenase (involved in degradation of dyes and hydrocarbons), and methyl accepting chemotaxis proteins (involved in response to chemotaxis) their crucial role in degradation of dye and hydrocarbon in polluted segments of river Yamuna (Table S11).

\section{Statistical analysis}

To detect the quantitative relationship between water and sediment quality parameters and microbial community structures and imperative function, we performed PCA to predict the relative abundance of microbiome at phylum level, phages and xenobiotic pathways from the measured values of parameters. Due to higher cumulative contribution rate of the first few principal components (PCs), we only focused on the first two PCs for correlation analysis. The relative abundance data of the phylum was used to compare the taxonomic compositions among these microbiomes in the three samples through PCA. At phylum level, PC1 vs. PC2 displayed that, sample 2 and 3 clustered into one group while sample 1 in another group, where Basidiomycota, Cyanobacteria, Tenericutes and Ascomycota formed the major cluster within sample 1 (Fig. 6A). The general dispersal of samples in PCA was found to be very similar with taxonomic composition as shown in Fig. 1. Subsequently, to identify the correlation between water and sediment quality parameters affecting major phylum's, we computed the correlations between the PC scores of all samples (as shown in Fig. S4 (A, B, C)). Most interestingly, we observed a good correlation between Sediment Avail $P$ with proteobacteria $(r=0.99)$, water Sp. Condition with firmicutes $(r=0.99)$, sediment OC with Actinobacteria, Water TDS with Chloroflexi $(r=0.99)$, Acidobacteria with water BOD $(r=$ 0.99) as evidenced from the scatterplot matrix shown in Fig. S4(A). Similarly, we also performed PCA of the phages with water and sediment quality parameters (Fig. 6B) where phages of sample 1 and 2 formed a major cluster. Prochlorococcus phage displayed a very good correlation with Water BOD $(r=$ 0.99), Bordetella phage showed correlation with water $\mathrm{pH}(\mathrm{r}=0.99)$, and Prochlorococcus had a good correlation with sediment total N and OC (Fig. S4(B)). Our PCA was extended to understand the correlation between xenobiotic degradation pathways with water and sediment quality parameters (Fig. 6C and Fig. S4(C)). Pathways involved metabolism of aromatic compounds including toluene, benzoate and chlorobenzoate, degradation which have been described as by-products of anaerobic degradation of hexachlorocyclohexane, were found to be positively correlated to the sediment total $\mathrm{N}$, sediment and water Sp. Cond., sediment total N (Fig. S4(C)). These results suggest those major differences in the microbial community structures, and their function reflects the differences in sediment and water quality parameters in the three polluted samples of River Yamuna.

\section{Discussion}

In developing countries like India, anthropogenic activities aided by rapid urbanization possesses a great threat to ecosystem due to unchecked pollution in freshwater aquatic system ecosystems. Among the 
tributary of Ganga, Yamuna which flows through Delhi is one the most polluted rivers in India due to accretion of numerous effluents, heavy metals, toxic chemicals, and xenobiotic compounds. The natural microflora plays a pivotal role in maintenance of rivers health and its ecosystem, but, continuous anthropogenic activities affect inherent microbiome and dynamics along with their biological functions. This study employs a whole genome metagenomic approach to unveil the community composition of microbiome and their putative function in different polluted stretches of river Yamuna.

All of the three samples shared certain microbial community architecture which was similar to previous study where Proteobacteria (Alphaproteobacteria, Betaproteobacteria, Deltaproteobacteria and Gammaproteobacteria) are highly dominating communities from Amazon riverine sediment metagenome (Ghai et al., 2011). In river Yamuna, these groups of bacteria constitute around $97 \%$ of the Proteobateria phylum, similar results were also documented by other researchers (Mittal et al., 2019b; Sodhi et al., 2021). Higher abundance of Betaproteobacteria and Gamma proteobacteria from the metagenomic data was also reported from urbanised area of stream sediments (Medeiros et al., 2016). High abundance of Deltaproteobacteirain all the three locations is substantiated by earlier study where it was reported that Deltaproteobacteria is a presiding class at different stretches of river Ganga and Yamuna (Samson et al., 2019). Deltaproteobacteria groups were also found to be dominant in freshwater lake sediments (White III et al., 2016). Presence of dominant anaerobic Deltaproteobacteria (of order Myxococcales, Desulfobacterales, Desulfuromonadales, and Myxococcales) in three sampling sites of the river Yamuna indicates anaerobic environmental conditions of the sediments, which is consistent with the water quality parameters having low dissolved oxygen level and high BOD. Further, Deltaproteobacteria has the physiological properties for iron and sulphate reduction, dehalogenation and fermentation (Liu et al., 2003). Gammaproteobacteria group of Proteobacteria are facultative anaerobes with assorted metabolic plasticity and plays a major role in nitrogen cycling (Franco et al., 2017). Betaproteobacteria, found as dominant class in the present study, was reported to be helpful in the nitrogen cycle and oxidizing ammonium to nitrate in freshwater aquatic environment (Tsagaraki et al., 2018). The abundance of Delta and Gamma Proteobacteria in the metagenome could be due to the presence of high domestic and industrial sewage in the Yamuna River water. It can also be denounced that the presence of these groups of bacteria in the sediments might be contributing significantly to the biogeochemical cycle processes in river Yamuna in the polluted stretch of Delhi.

Presence of genus Dechloromonas in river sediment indicate their role in degradation of xenobiotic pollutants (Zhang et al., 2021). Though it is quite difficult to establish taxonomy assignments at species level using metagenome reads, but our study identified some important species involved in biogeochemical cycle and degradation of various pollutants. Notably, Dechloromonas aeromatica (capable of degrading benzoates and hydrocarbon pollution) (Coates et al., 2001; Nitz et al., 2020); Syntrophus aciditrophicus (degrading aromatic compounds) (James et al., 2019); Rhodopseudomonas palustris (involved in biodegradation of hexabromocyclododecane) (Chang et al., 2020); and Syntrophobacter fumaroxidans (sulfate reducing bacteria) (Jantharadej et al., 2020) were abundant in polluted stretches of river Yamuna. 
Archaea plays a pivotal role in environmental microbial community architecture (Jarrell et al., 2011), however ecological roles of the archaeal community in freshwater aquatic environments have not been explored in detail like bacteria (Von Schiller et al., 2017). Methanogens utilizes acetate as sole source of energy and are the major group in the methanogenic microbe diversity (Vítězová et al., 2020)in waste water sewage. Most of archaea found were methanogens, which signifies their involvement in the biogenic process for methanogenesis activity (Wu et al., 2021) in river sediments, similar findings were also reported by Rathore and co-workers (Rathour et al., 2020) in Pangong lake. Methanogenes are abundant in waste water (Tabatabaei et al., 2010), which is the reason, in the present study most archaea found are methanogen, as the sediment were sampled from the polluted sites of river Yamuna.

The ubiquitous presence of fungi in freshwater aquatic ecosystem indicates their intricate role in functioning of the food web dynamics (Ittner et al., 2018). Among the fungal communities, the presence of Ascomycota group in river Yamuna may attributed due to the decay of the organic matter and consequent cycling of nutrients. The genera belonging to Trichocomaceae family are capable of secreting pharmacologically important secondary metabolites including penicillin, lovastatin, etc. were found to be highly abundant all three metagenome (Houbraken and Samson, 2011). The presence of genera Aspergillus and Penicillium can be correlated with the presence of faecal matters in the sediments (Arvanitidou et al., 2005). Also, presence of various opportunistic fungal pathogens like Penicillium, Coccidioides and Aspergillus, involved in respiratory tract infections and onychomycosis could be correlated with the pollution mediated water-borne diseases (De Oliveira et al., 2015). As these genera of fungal species depict the ecological and trophic state of aquatic ecosystems, they can be considered as important bioindicator species of pollution due to colossal anthropic activities in Yamuna (Liu et al., 2017; Zhang et al., 2019).

Virus plays an important role in microbial ecology including biogeochemical cycle of the environment (He et al., 2017). Bacteriophages are the virus and commonly known as phage and can control the proliferation of bacteria or archaea by infecting and replicating within them. Caudovirales were reported previously as the dominating phages in aquatic ecosystem, where freshwater is having domestic sewages as the discharge (Kim et al., 2017; Parmar et al., 2018a). Myoviridae family was found abundantly among Caudovirales phage, along with other dominant families Siphoviridae and Podoviridae, which is similar to result of other researchers in fresh water sediments (Parmar et al., 2018b). In the present study T-4 like virus was the most common phage genus at family level. T-4 like virus has elongated head with long contractile tail having 5-hydroxymethylcytosine and encoding a type B DNA polymerase (Maniloff et al., 1999). The phage belongs to genus, BPP-1 found in this study, is a short-tailed dsDNA phage of family Podoviridae (Doulatov et al., 2004; Liu et al., 2002)and infects Bordetella species which causes whopping cough by infecting respiratory epithelial surfaces in humans (Dai et al., 2010). Phages play a significant role in driving evolution in prokaryotes through horizontal gene transfer and also regulates population of specific bacteria in selective niches (Elbreki et al., 2014).

Principal component analysis showed a great degree of positive correlation between abundance of microbiome with sediment and water quality parameters. These results were consistent with earlier 
studies that alteration in sediment and water quality parameters affects the community structure of microbiome (Lu et al., 2017; Mittal et al., 2019a). Therefore, we further hypothesize that microbial communities could be affected by continuous anthropogenic activities mostly due to domestic and industrial wastes.

The metabolic functioning of freshwater ecosystem driven by microbes can be understood by exploiting the functional potential of genes encoded by these microbiomes. Therefore, it is of immense importance to unveil the functional potential of microbiomes from polluted stretches using the metagenomic reads. SEED analysis identified the genes involved in sulfur metabolism, which is consistent with the presence of Deltaproteobacteria group (mostly family of Desulfobacteraceae, Desulfobulbaceae, Desulfomicrobiaceae, Desulfovibrionaceae and Geobacteraceae), involved in sulphate reduction (Sonthiphand et al., 2019). Similarly, COG analysis shown the presence of genes associated with defense mechanism, which was supported by the presence of antimicrobial genes and multi drug resistant efflux pump genes in the sediment metagenomes (Bombaywala et al., 2021). Furthermore, these results are in agreement with a recent study on metagenomics of river Yamuna by Das and co-workers (Das et al., 2020b).

Among the major pathways, amino acid metabolism, carbohydrate metabolism, membrane transport and energy metabolism were significant enriched in the polluted microbiomes of river Yamuna regardless of their pollution level. The abundance of Proteobacteria, Bacteroidetes, Firmicutes and Actinobacteria predicted using SEED could be correlated with their role in nutrient cycling, carbon metabolism, membrane transport system and stress response regulatory system (Ahmad et al., 2021; Koo et al., 2017). Among the family of transporters, the largest known protein family $A B C$ transporters were significantly enriched in all samples signifies their participation in transportation of carbohydrates, lipids, proteins and inorganic nutrients across the membrane (ter Beek et al., 2014). The presence of members of different families (including ompR, chemotaxis, PleD, LitB and Ntrc) (Fig. S5) involved in two-component signal transduction systems indicate the role of bacteria to signal transduction mechanism in response to environment and other their intracellular cues. Moreover, it has been suggested that consortia of microbiome can alters cellular physiological activities i.e., initiation of gene expression, catabolic activities and protein-protein interactions through two-component systems (Giuliani et al., 2011).

Aromatic compounds are the second most predominant pollutants in ecosystem, therefore, identification and quantification of such genes involved in degradation of such compounds are useful in the context of pollution research in aquatic environment. KEGG orthology at level 3 , identified the genes involved in the degradation of various xenobiotic compounds under category "Xenobiotics biodegradation and metabolism". Majority of the reads were mapped to the genes involved in Benzoate, Nitrotoluene, Cholorocyclohexane and Chlorobenzene, and drug metabolism.

KEGG ortholog analysis revealed the presence of "Xenobiotics biodegradation and metabolism" genes in all the samples, where taxonomic classification informed about the presence of bacteria involved in degradation of various xenobiotic compounds (Dechloromonas aromatica: benzene reducing; 
Rhodopseudomonas palustris: organic matter reducing, and Syntrophus aciditrophicus: fatty acid reducing). Furthermore, benzoate, nitrotoluene, aminobenzoate, drug metabolism, and polycyclic aromatic hydrocarbons degrading genes were found in this study were similar with findings from polluted rivers (Yadav et al., 2021a). Moreover, a good correlation between various water and sediment quality parameters and the pathways involved in degradation of end products of hexachlorocyclohexane (one of the highly toxic organochlorine xenobiotic compound) and other xenobiotic compounds indicates that under the stress of various pollutants, microbiome community develops diverse metabolic functions to adapt to the changes in habitats (Mishra et al., 2021; Zhang et al., 2020). Presence of PDEs like peroxidases in polluted river sediment signifies their role in degradation of recalcitrant dyes and other xenobiotic compounds such as phenol (Bansal and Kanwar, 2013). Furthermore, highly abundant 4hydroxybenzoate monooxygenase, biphenyl 2,3-dioxygenase and chemotaxis protein III detected in this study implies their participation in degradation of dye, hydrocarbons, and to sense environmental cues (Sankara Subramanian et al., 2020; Yadav et al., 2021b). Overall, our study has contributed in understanding the microbiome community structure and their functions in the sediments of river Yamuna. More samples and a greater number of studies are required to identify novel enzymes, species and comprehensive degradation pathways of various aromatic compounds from sediments of polluted river like Yamuna which may have significant applications in industrial biotechnology and bioremediation.

\section{Conclusion}

In this study, metagenomic analysis of sediments of river Yamuna provides new insights into the community structure and their plausible function of microbiome in three polluted stretches at Delhi. River sediment metagenome data analysis revealed the alterations in taxonomic and functional profiles of sediment microbiome under different stressed condition due to diverse pollutants. Higher abundance of Methanosaeta, Beta, Gamma and Delta-Proteobacteria were observed in the Yamuna River sediments located within close proximity of industries. Our study also revealed the potential for methane production, metal reduction and other bioremedial properties of the microorganisms present in the polluted sediments of river Yamuna. Filtration of Mycobiome reads from metagenome data revealed a number fungal species i.e., human pathogens, plant pathogens and toxin producers. Furthermore, occurrence of fungal genera Aspergillus and Penicillium designate mycobiomes as potential bio-indicators of river pollution, while dominant nature of Lodderomyces, and Nakaseomyces implies their intricate role in eutrophication. The functional analysis of genes from sediment microbiome revealed major pathways related to the degradation of xenobiotic compounds including benzoate, DDT, toluene, and caprolactam were significantly enriched in the sediments of polluted stetches of river Yamuna. The presence of genes for chemotaxis permits microbes to sense environmental cues, and genes with organic and xenobiotic compound degradation properties corresponds to the anthropogenic activities with bioremedial properties. The information on the microbial community structures of the sediments of river Yamuna and their functional properties would significantly contribute to the biogeochemical cycle in the river 
ecosystem. Finally, we believe that the findings would be also helpful for the sustainable management of river health.

\section{Declarations}

\section{Availability of Data and Material}

The datasets presented in this study can be found in online repositories of SRA at NCBI (SRS4592195, SRS4592470, and SRS4600533).

Ethics approval and consent to participate: Not applicable

Consent for publication: Not applicable

\section{Funding}

This study was supported by the grant from CABin program of Session 2020-2025by the ICAR - Indian Agricultural Statistics Research Institute, New Delhi.

\section{Author's contributions}

Pranaya Kumar Parida: investigation, data analysis, original draft preparation,

Bijay Kumar Behera: Conceptualization, methodology, investigation

Budheswar Dehury: data interpretation, data analysis, writing

Ajaya Kumar Rout: writing, data analysis

Dhruba Jyoti Sarkar: writing and statistical analysis

Anil Rai: Data analysis, critical revision

Basanta Kumar Das: visualization, investigation

Trilochan Mohapatra: Supervision

\section{Competing Interest}

The authors declare that no potential competing interest.

\section{Acknowledgments}

We acknowledged Mr. Asim Kumar Jana, Senior Technical Assistant of ICAR-CIFRI, Barrackpore, Kolkata for sample collection and providing technical support. 


\section{References}

1. Abatenh E, Gizaw B, Tsegaye Z, Wassie M (2017) The role of microorganisms in bioremediation-A review. Open Journal of Environmental Biology 2:38-46

2. Abia ALK, Alisoltani A, Keshri J, Ubomba-Jaswa E (2018) Metagenomic analysis of the bacterial communities and their functional profiles in water and sediments of the Apies River, South Africa, as a function of land use. Sci Total Environ 616:326-334

3. Ahmad T, Gupta G, Sharma A, Kaur B, El-Sheikh MA, Alyemeni MN (2021) Metagenomic analysis exploring taxonomic and functional diversity of bacterial communities of a Himalayan urban fresh water lake.PloS one16, e0248116

4. Alves L, de Westmann F, Lovate CA, de Siqueira GL, Borelli GMV, Guazzaroni TC (2018) M.-E., Metagenomic approaches for understanding new concepts in microbial science. International journal of genomics 2018

5. APHA AWWA WEF (2012a) Standard Methods for the Examination of Water and Wastewater, 22nd Edn. https://doi.org/10.2105/AJPH.51.6.940-a

6. APHA AWWA WEF (2012b) Standard Methods for the Examination of Water and Wastewater, 22nd Edn. https://doi.org/10.2105/AJPH.51.6.940-a

7. Arvanitidou M, Kanellou K, Vagiona DG (2005) Diversity of Salmonella spp. and fungi in northern Greek rivers and their correlation to fecal pollution indicators. Environ Res 99:278-284

8. Bansal N, Kanwar SS (2013) Peroxidase (s) in environment protection. The Scientific World Journal 2013. https://doi.org/https://doi.org/10.1155/2013/714639

9. Behera B, Kumar, Chakraborty HJ, Patra B, Rout AK, Dehury B, Das BK, Sarkar DJ, Parida PK, Raman RK, Rao AR (2020a) Metagenomic Analysis Reveals Bacterial and Fungal Diversity and Their Bioremediation Potential From Sediments of River Ganga and Yamuna in India. Front Microbiol 11:2531. https://doi.org/10.3389/fmicb.2020.556136

10. Behera BK, Patra B, Chakraborty HJ, Sahu P, Rout AK, Sarkar DJ, Parida PK, Raman RK, Rao AR, Rai A, Das BK, Jena J, Mohapatra T (2020b) Metagenome analysis from the sediment of river Ganga and Yamuna: In search of beneficial microbiome. PLoS ONE 15.

https://doi.org/10.1371/journal.pone.0239594

11. Bombaywala S, Purohit HJ, Dafale NA (2021) Mobility of antibiotic resistance and its co-occurrence with metal resistance in pathogens under oxidative stress. J Environ Manage 297:113315

12. Brenner DJ, Krieg NR, Staley JT, Garrity GM (2005) Bergey's manual ${ }^{\circledR}$ of systematic bacteriology: volume two: The proteobacteria, part A introductory essays. Springer

13. Buchfink B, Xie C, Huson DH (2015) Fast and sensitive protein alignment using DIAMOND. Nat Methods 12:59-60. https://doi.org/10.1038/nmeth.3176

14. Cabral L, Noronha MF, de Sousa STP, Lacerda-Júnior GV, Richter L, Fostier AH, Andreote FD, Hess M, de Oliveira VM (2019) The metagenomic landscape of xenobiotics biodegradation in mangrove sediments. Ecotoxicol Environ Saf 179:232-240 
15. Chang T-H, Wang R, Peng Y-H, Chou T-H, Li Y-J, Shih Y (2020) Biodegradation of hexabromocyclododecane by Rhodopseudomonas palustris YSC3 strain: A free-living nitrogen-fixing bacterium isolated in Taiwan. Chemosphere 246:125621

16. Chen H, Bai X, Jing L, Chen R, Teng Y (2019) Characterization of antibiotic resistance genes in the sediments of an urban river revealed by comparative metagenomics analysis. Sci Total Environ 653:1513-1521

17. Chu BTT, Petrovich ML, Chaudhary A, Wright D, Murphy B, Wells G, Poretsky R (2018) Metagenomics reveals the impact of wastewater treatment plants on the dispersal of microorganisms and genes in aquatic sediments. Applied and environmental microbiology 84

18. Coates JD, Chakraborty R, Lack JG, O’Connor SM, Cole KA, Bender KS, Achenbach LA (2001) Anaerobic benzene oxidation coupled to nitrate reduction in pure culture by two strains of Dechloromonas. Nature 411:1039-1043

19. CPCB, Annual, Report (2018) 2017-18. Central Pollution Control Board, Ministry of Environment, Forest \& Climate Change, Government of India

20. CWC (2011) "Hot spots" in rivers of India

21. Dai W, Hodes A, Hui WH, Gingery M, Miller JF, Zhou ZH (2010) Three-dimensional structure of tropism-switching Bordetella bacteriophage. Proceedings of the National Academy of Sciences 107, 4347-4352

22. Darzi Y, Yamate Y, Yamada T (2019) FuncTree2: an interactive radial tree for functional hierarchies and omics data visualization. Bioinformatics 35:4519-4521. https://doi.org/10.1093/bioinformatics/btz245

23. Das BK, Behera BK, Chakraborty HJ, Paria P, Gangopadhyay A, Rout AK, Nayak KK, Parida PK, Rai A (2020a) Metagenomic study focusing on antibiotic resistance genes from the sediments of River Yamuna. https://doi.org/10.1016/j.gene.2020.144951. Gene 758

24. Das BK, Behera BK, Chakraborty HJ, Paria P, Gangopadhyay A, Rout AK, Nayak KK, Parida PK, Rai A (2020b) Metagenomic study focusing on antibiotic resistance genes from the sediments of River Yamuna. https://doi.org/10.1016/j.gene.2020.144951. Gene 758

25. De Oliveira HC, Assato PA, Marcos CM, Scorzoni L, de Paula E, Silva ACA, Da Silva JDF, Singulani J, de Alarcon L, Fusco-Almeida KM, Mendes-Giannini AM, M.J.S (2015) Paracoccidioides-host interaction: an overview on recent advances in the paracoccidioidomycosis. Front Microbiol 6:1319

26. Doulatov S, Hodes A, Dai L, Mandhana N, Liu M, Deora R, Simons RW, Zimmerly S, Miller JF (2004) Tropism switching in Bordetella bacteriophage defines a family of diversity-generating retroelements. Nature 431:476-481

27. Elbreki M, Ross RP, Hill C, O’Mahony J, McAuliffe O, Coffey A (2014) Bacteriophages and their derivatives as biotherapeutic agents in disease prevention and treatment. Journal of Viruses 2014. https://doi.org/10.1155/2014/382539

28. Franco DC, Signori CN, Duarte RTD, Nakayama CR, Campos LS, Pellizari VH (2017) High prevalence of gammaproteobacteria in the sediments of admiralty bay and north bransfield Basin, Northwestern 
Antarctic Peninsula. Front Microbiol 8:153. https://doi.org/10.3389/fmicb.2017.00153

29. Ghai R, Rodŕíguez-Valera F, McMahon KD, Toyama D, Rinke R, de Oliveira TCS, Garcia JW, de Miranda FP, Henrique-Silva F (2011) Metagenomics of the water column in the pristine upper course of the Amazon river. PLoS ONE 6:e23785

30. Gibbons SM, Jones E, Bearquiver A, Blackwolf F, Roundstone W, Scott N, Hooker J, Madsen R, Coleman ML, Gilbert JA (2014) Human and environmental impacts on river sediment microbial communities.PloS one9, e97435

31. Giuliani SE, Frank AM, Corgliano DM, Seifert C, Hauser L, Collart FR (2011) Environment sensing and response mediated by $A B C$ transporters. BMC Genomics 12:1-14

32. He M, Cai L, Zhang C, Jiao N, Zhang R (2017) Phylogenetic diversity of T4-type phages in sediments from the subtropical pearl river estuary. Front Microbiol 8:897.

https://doi.org/10.1016/j.margen.2019.100718

33. Himmelberg AM, Brüls T, Farmani Z, Weyrauch P, Barthel G, Schrader W, Meckenstock RU (2018) Anaerobic degradation of phenanthrene by a sulfate-reducing enrichment culture. Environ Microbiol $20: 3589-3600$

34. Houbraken J, Samson RA (2011) Phylogeny of Penicillium and the segregation of Trichocomaceae into three families. Stud Mycol 70:1-51

35. Huson DH, Auch AF, Qi J, Schuster SC (2007) MEGAN analysis of metagenomic data. Genome Res $17: 377-386$

36. Ittner LD, Junghans M, Werner I (2018) Aquatic fungi: a disregarded trophic level in ecological risk assessment of organic fungicides. Frontiers in Environmental Science 6:105

37. Iyer R, Damania A (2020) Shotgun metagenomics of indigenous bacteria collected from the banks of the San Jacinto River for biodegradation of aromatic waste. FEMS Microbiol Lett 367:fnaa133

38. Jain SK, Agarwal PK, Singh VP (2007) Hydrology and water resources of India. Springer Science \& Business Media

39. James KL, Kung JW, Crable BR, Mouttaki H, Sieber JR, Nguyen HH, Yang Y, Xie Y, Erde J, Wofford NQ (2019) Syntrophusaciditrophicus uses the same enzymes in a reversible manner to degrade and synthesize aromatic and alicyclic acids. Environ Microbiol 21:1833-1846

40. Jantharadej K, Mhuantong W, Limpiyakorn T, Mongkolsuk S, Sirikanchana K, Suwannasilp BB (2020) Identification of sulfate-reducing and methanogenic microbial taxa in anaerobic bioreactors from industrial wastewater treatment plants using next-generation sequencing and gene clone library analyses. Journal of Environmental Science and Health Part A 55:1283-1293

41. Jarrell KF, Walters AD, Bochiwal C, Borgia JM, Dickinson T, Chong JPJ (2011) Major players on the microbial stage: why archaea are important. Microbiology 157:919-936

42. Kanehisa M, Furumichi M, Tanabe M, Sato Y, Morishima K (2017) KEGG: new perspectives on genomes, pathways, diseases and drugs. Nucleic Acids Res 45:D353-D361 
43. Kim Y, Van Bonn W, Aw TG, Rose JB (2017) Aquarium viromes: viromes of human-managed aquatic systems. Front Microbiol 8:1231

44. Koo H, Mojib N, Hakim JA, Hawes I, Tanabe Y, Andersen DT, Bej AK (2017) Microbial communities and their predicted metabolic functions in growth laminae of a unique large conical mat from Lake Untersee, East Antarctica. Front Microbiol 8:1347

45. Liu K-H, Ding X-W, Narsing Rao MP, Zhang B, Zhang Y-G, Liu F-H, Liu B-B, Xiao M, Li W-J (2017) Morphological and transcriptomic analysis reveals the osmoadaptive response of endophytic fungus Aspergillus montevidensis ZYD4 to high salt stress. Front Microbiol 8:1789

46. Liu M, Deora R, Doulatov SR, Gingery M, Eiserling FA, Preston A, Maskell DJ, Simons RW, Cotter PA, Parkhill J (2002) Reverse transcriptase-mediated tropism switching in Bordetella bacteriophage. Science 295:2091-2094

47. Liu X, Bagwell CE, Wu L, Devol AH, Zhou J (2003) Molecular diversity of sulfate-reducing bacteria from two different continental margin habitats. Appl Environ Microbiol 69:6073

48. Lu X-M, Chen C, Zheng T-L (2017) Metagenomic insights into effects of chemical pollutants on microbial community composition and function in estuarine sediments receiving polluted river water. Microb Ecol 73:791-800

49. Maniloff J, Ackermann H-W, Jarvis A (1999) Phage taxonomy and classification. https://doi.org/10.1006/rwvi.1999.0024

50. Medeiros JD, Cantão ME, Cesar DE, Nicolás MF, Diniz CG, Silva VL, de Vasconcelos ATR, Coelho CM (2016) Comparative metagenome of a stream impacted by the urbanization phenomenon. Brazilian Journal of Microbiology 47:835-845

51. Meyer F, Paarmann D, D'Souza M, Olson R, Glass EM, Kubal M, Paczian T, Rodriguez A, Stevens R, Wilke A (2008) The metagenomics RAST server-a public resource for the automatic phylogenetic and functional analysis of metagenomes. BMC Bioinformatics 9:1-8. https://doi.org/10.1002/9781118010518.ch37

52. Mishra S, Lin Z, Pang S, Zhang W, Bhatt P, Chen S (2021) Recent advanced technologies for the characterization of xenobiotic-degrading microorganisms and microbial communities. Front Bioeng Biotechnol 9:31

53. Mitchell AL, Almeida A, Beracochea M, Boland M, Burgin J, Cochrane G, Crusoe MR, Kale V, Potter SC, Richardson LJ (2020) MGnify: the microbiome analysis resource in 2020. Nucleic Acids Res 48:D570-D578. https://doi.org/10.1093/nar/gkz1035

54. Mittal P, PK VP, Dhakan DB, Kumar S, Sharma VK (2019a) Metagenome of a polluted river reveals a reservoir of metabolic and antibiotic resistance genes. Environmental Microbiome 14:1-12

55. Mittal P, PK VP, Dhakan DB, Kumar S, Sharma VK (2019b) Metagenome of a polluted river reveals a reservoir of metabolic and antibiotic resistance genes. Environmental Microbiome 14:1-12

56. Muthaiyah NP (2020) Rejuvenating Yamuna River by Wastewater Treatment and Management. International Journal of Energy and Environmental Science 5:14 
57. Nitz H, Duarte M, Jauregui R, Pieper DH, Müller JA, Kästner M (2020) Identification of benzenedegrading Proteobacteria in a constructed wetland by employing in situ microcosms and RNA-stable isotope probing. Appl Microbiol Biotechnol 104:1809-1820

58. Overbeek R, Begley T, Butler RM, Choudhuri JV, Chuang H-Y, Cohoon M, de Crécy-Lagard V, Diaz N, Disz T, Edwards R (2005a) The subsystems approach to genome annotation and its use in the project to annotate 1000 genomes. Nucleic Acids Res 33:5691-5702

59. Overbeek R, Begley T, Butler RM, Choudhuri JV, Chuang H-Y, Cohoon M, de Crécy-Lagard V, Diaz N, Disz T, Edwards R (2005b) The subsystems approach to genome annotation and its use in the project to annotate 1000 genomes. Nucleic Acids Res 33:5691-5702

60. Parmar K, Dafale N, Pal R, Tikariha H, Purohit H (2018a) An insight into phage diversity at environmental habitats using comparative metagenomics approach. Curr Microbiol 75:132-141. https://doi.org/10.1007/s00284-017-1357-0

61. Parmar K, Dafale N, Pal R, Tikariha H, Purohit H (2018b) An insight into phage diversity at environmental habitats using comparative metagenomics approach. Curr Microbiol 75:132-141. https://doi.org/10.1007/s00284-017-1357-0

62. Rathour R, Gupta J, Mishra A, Rajeev AC, Dupont CL, Thakur IS (2020) A comparative metagenomic study reveals microbial diversity and their role in the biogeochemical cycling of Pangong lake. Sci Total Environ 731:139074

63. Reddy B, Dubey SK (2019a) River Ganges water as reservoir of microbes with antibiotic and metal ion resistance genes: High throughput metagenomic approach. Environ Pollut 246:443-451

64. Reddy B, Dubey SK (2019b) River Ganges water as reservoir of microbes with antibiotic and metal ion resistance genes: High throughput metagenomic approach. Environ Pollut 246:443-451

65. Samson R, Shah M, Yadav R, Sarode P, Rajput V, Dastager SG, Dharne MS, Khairnar K (2019) Metagenomic insights to understand transient influence of Yamuna River on taxonomic and functional aspects of bacterial and archaeal communities of River Ganges. Sci Total Environ 674:288-299

66. Sankara Subramanian SH, Balachandran KRS, Rangamaran VR, Gopal D (2020) RemeDB: tool for rapid prediction of enzymes involved in bioremediation from high-throughput metagenome data sets. J Comput Biol 27:1020-1029. https://doi.org/10.1089/cmb.2019.0345

67. Simon C, Daniel R (2009) Achievements and new knowledge unraveled by metagenomic approaches. Appl Microbiol Biotechnol 85:265-276

68. Sodhi KK, Kumar M, Singh DK (2021) Assessing the bacterial diversity and functional profiles of the River Yamuna using Illumina MiSeq sequencing. Arch Microbiol 203:367-375. https://doi.org/10.1007/s00203-020-02045-0

69. Tabatabaei M, Rahim RA, Abdullah N, Wright A-DG, Shirai Y, Sakai K, Sulaiman A, Hassan MA (2010) Importance of the methanogenic archaea populations in anaerobic wastewater treatments. Process Biochem 45:1214-1225 
70. Tatusov RL, Galperin MY, Natale DA, Koonin EV (2000) The COG database: a tool for genome-scale analysis of protein functions and evolution. Nucleic Acids Res 28:33-36

71. ter Beek J, Guskov A, Slotboom DJ (2014) Structural diversity of ABC transporters. J Gen Physiol 143:419-435

72. Tsagaraki TM, Pree B, Leiknes $\varnothing$, Larsen A, Bratbak G, Øvreås L, Egge JK, Spanek R, Paulsen ML, Olsen $Y$ (2018) Bacterial community composition responds to changes in copepod abundance and alters ecosystem function in an Arctic mesocosm study. ISME J 12:2694-2705

73. Vítězová M, Kohoutová A, Vítěz T, Hanišáková N, Kushkevych I (2020) Methanogenic Microorganisms in Industrial Wastewater Anaerobic Treatment Processes 8:1546

74. Von Schiller D, Acuña V, Aristi I, Arroita M, Basaguren A, Bellin A, Boyero L, Butturini A, Ginebreda A, Kalogianni E (2017) River ecosystem processes: A synthesis of approaches, criteria of use and sensitivity to environmental stressors. Sci Total Environ 596:465-480

75. Wang Y, Wegener G, Ruff SE, Wang F (2021) Methyl/alkyl-coenzyme M reductase-based anaerobic alkane oxidation in archaea. Environ Microbiol 23:530-541

76. White III, Chan RA, Gavelis AM, Leander GS, Brady BS, Slater AL, Lim GF, Suttle DSS, C.A (2016) Metagenomic analysis suggests modern freshwater microbialitesharbor a distinct core microbial community. Front Microbiol 6:1531

77. Wu D, Zhao Y, Cheng L, Zhou Z, Wu Q, Wang Q, Yuan Q (2021) Activity and structure of methanogenic microbial communities in sediments of cascade hydropower reservoirs, Southwest China. Science of The Total Environment 147515.

78. Yadav R, Rajput V, Dharne M (2021a) Functional metagenomic landscape of polluted river reveals potential genes involved in degradation of xenobiotic pollutants. Environ Res 192:110332

79. Yadav R, Rajput V, Dharne M (2021b) Functional metagenomic landscape of polluted river reveals potential genes involved in degradation of xenobiotic pollutants. Environ Res 192:110332

80. Yan Z, Hao Z, Wu H, Jiang H, Yang M, Wang C (2019) Co-occurrence patterns of the microbial community in polycyclic aromatic hydrocarbon-contaminated riverine sediments. J Hazard Mater 367:99-108

81. Zhang S, Amanze C, Sun C, Zou K, Fu S, Deng Y, Liu X, Liang Y (2021) Evolutionary, genomic, and biogeographic characterization of two novel xenobiotics-degrading strains affiliated with Dechloromonas. Heliyon e07181.

82. Zhang S, Tsementzi D, Hatt JK, Bivins A, Khelurkar N, Brown J, Tripathi SN, Konstantinidis KT (2019) Intensive allochthonous inputs along the Ganges River and their effect on microbial community composition and dynamics. Environ Microbiol 21:182-196

83. Zhang W, Lin Z, Pang S, Bhatt P, Chen S (2020) Insights into the biodegradation of lindane ( $Y$ hexachlorocyclohexane) using a microbial system. Front Microbiol 11:522

\section{Figures}



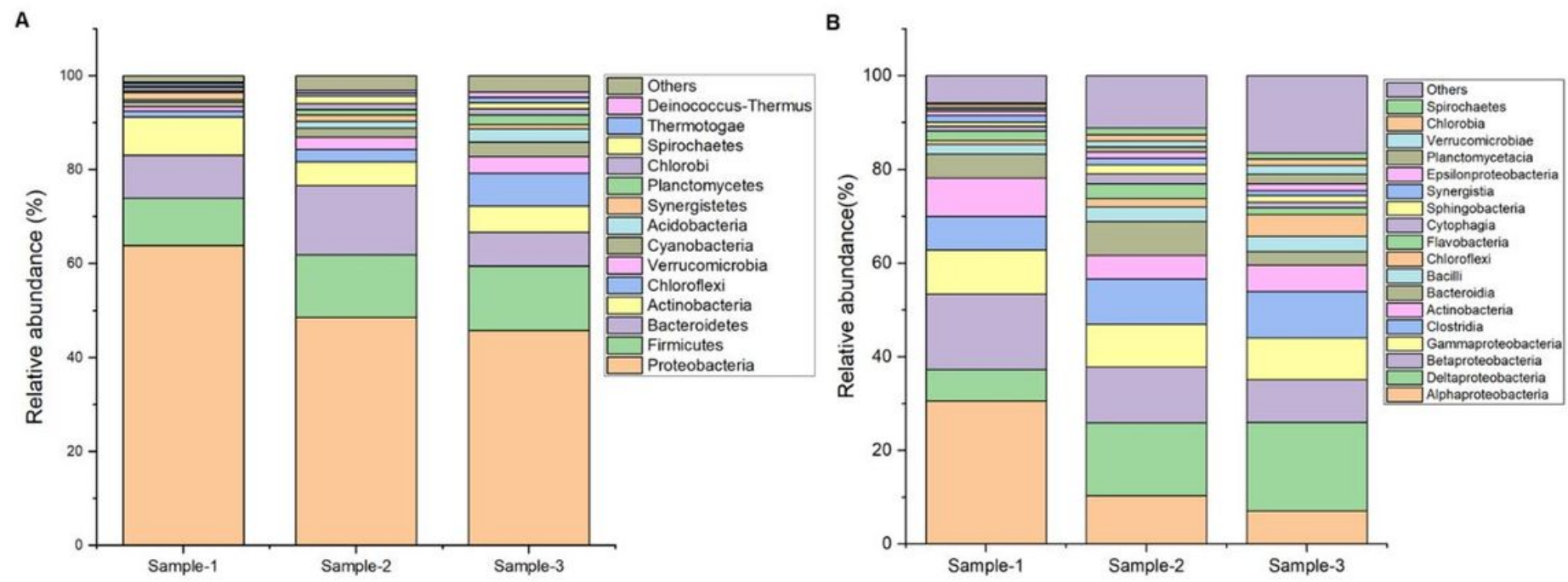

Figure 1

Relative abundance of microbiota at different level of taxonomy in the sediment sites of river Yamuna.

(A) Composition of microbes at phylum level in three sampling sites of polluted stretch of Delhi from Yamuna River showing higher proportion of Protobacteria group in each sample. (B) Composition at microbiome at class level different sampling sites of river Yamuna. 


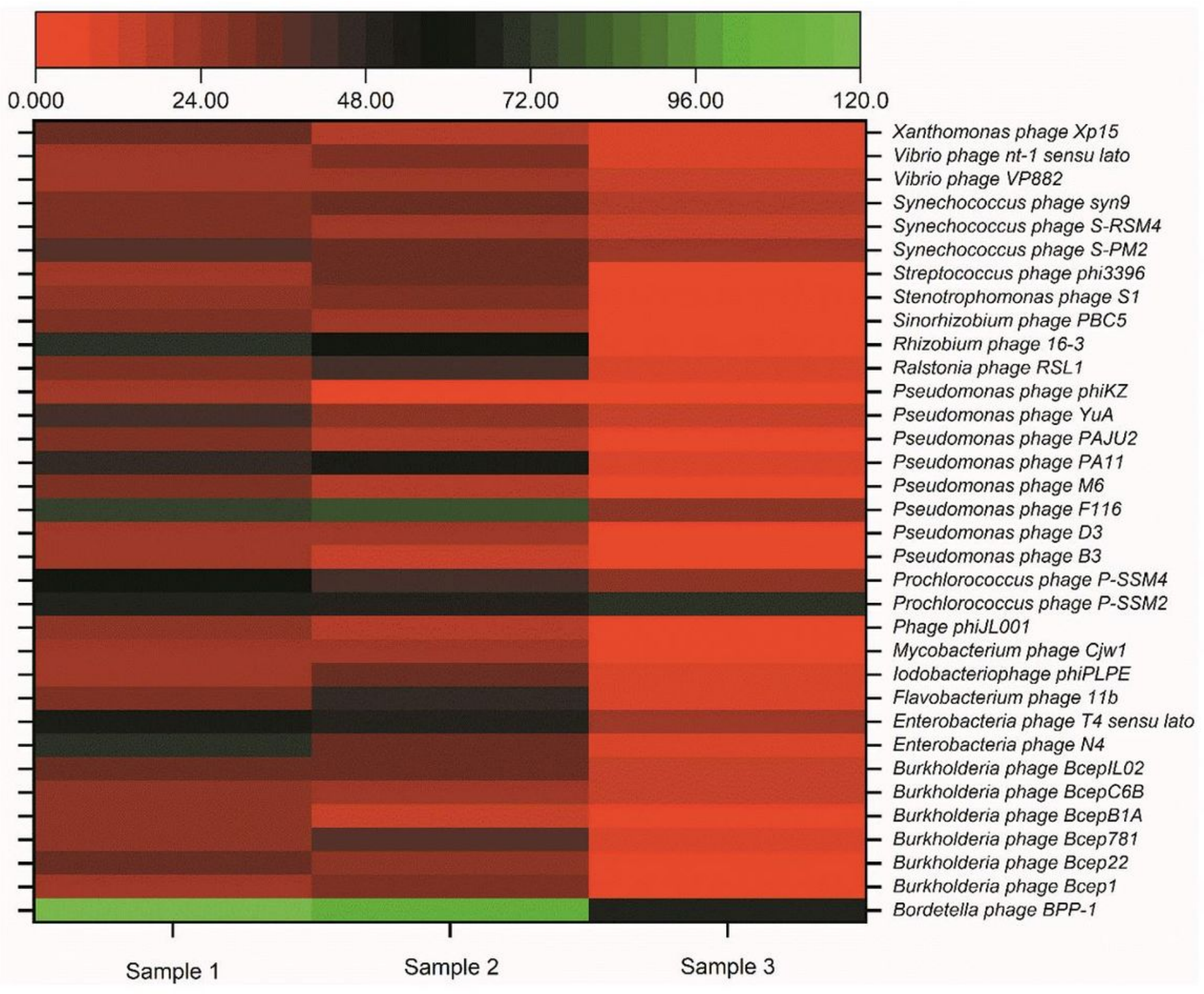

\section{Figure 2}

Distribution of phages in the three sediment metagenome data of river Yamuna. Heat map showing the abundance of phages from three sampling sites of polluted stretch of Delhi, River Yamuna. 
A

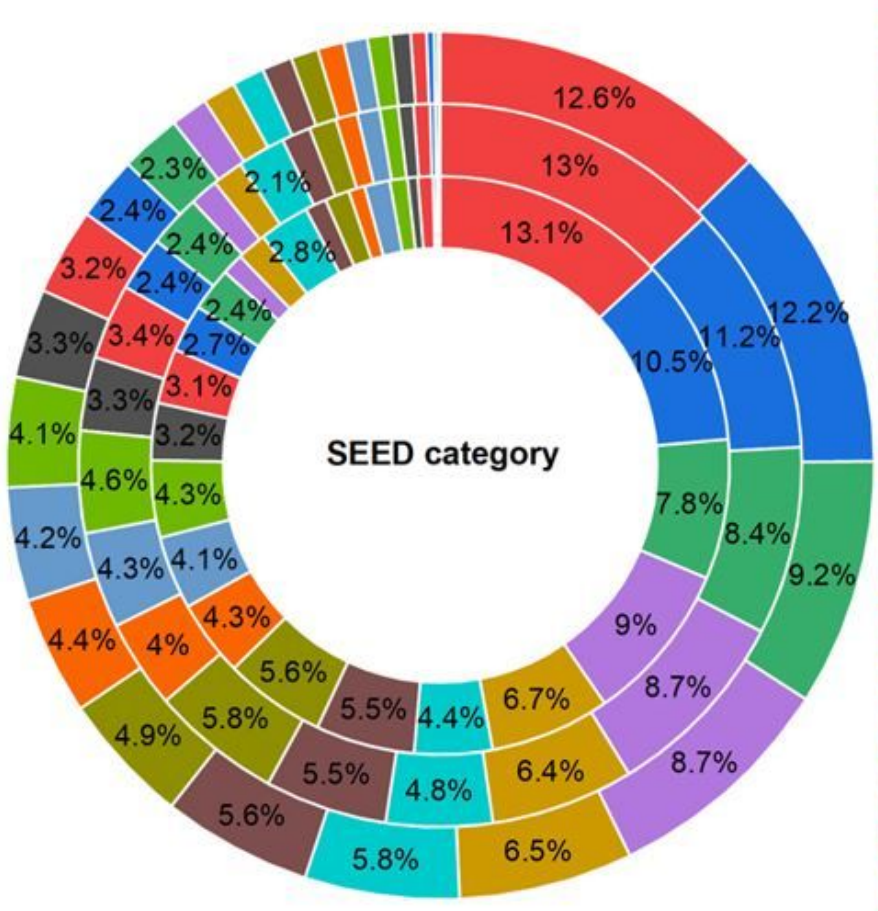

B

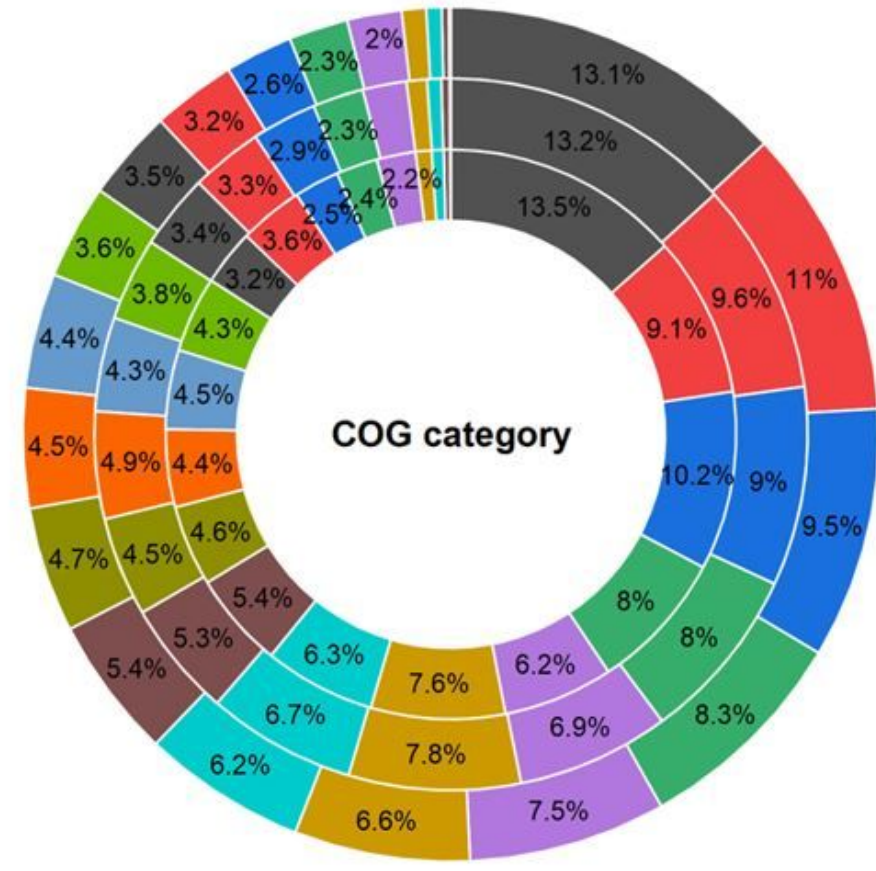

Clustering-based subsystems

Carbohydrates

Protein Metabolism

Amino Acids and Derivatives

Miscellaneous

Respiration

Cofactors, Vitamins, Prosthetic Groups, Pigments

DNA Metabolism

Membrane Transport

RNA Metabolism

Cell Wall and Capsule

Nucleosides and Nucleotides

Virulence, Disease and Defense

Stress Response

Fatty Acids, Lipids, and Isoprenoids

Phosphorus Metabolism

Nitrogen Metabolism

Phages, Prophages, Transposable elements, Plasmids

Motility and Chemotaxis

Regulation and Cell signaling

Cell Division and Cell Cycle

Metabolism of Aromatic Compounds

Sulfur Metabolism

Potassium metabolism

Iron acquisition and metabolism

Secondary Metabolism

Dormancy and Sporulation

Photosynthesis

General function prediction only

Energy production and conversion

Amino acid transport and metabolism

Translation, ribosomal structure and biogenesis

Carbohydrate transport and metabolism

Replication, recombination and repair

Cell wall/membrane/envelope biogenesis

Inorganic ion transport and metabolism

Posttranslational modification, protein turnover, chaperones

Signal transduction mechanisms

Coenzyme transport and metabolism

Lipid transport and metabolism

Nucleotide transport and metabolism

Transcription

Defense mechanisms

Intracellular trafficking, secretion, and vesicular transport

Secondary metabolites biosynthesis, transport and catabolism

Cell cycle control, cell division, chromosome partitioning

Function unknown

Cell motility

Chromatin structure and dynamics

Cytoskeleton

RNA processing and modification

Extracellular structures

\section{Figure 3}

\section{Functional classification through SEED and COG subsystem of microbial activity of microbes from}

polluted stretch of Delhi at three sampling sites of river Yamuna. (A) Functional categories of genes annotated through SEED-subsystems (B) Doughnut chart representing the different functional categories of genes from three samples microbiome data through COG analysis. The graph shows only $>2 \%$ at different levels for clarity (Inner circle: sample 1, Middle circle: sample 2 and Outer circle: sample 3). 


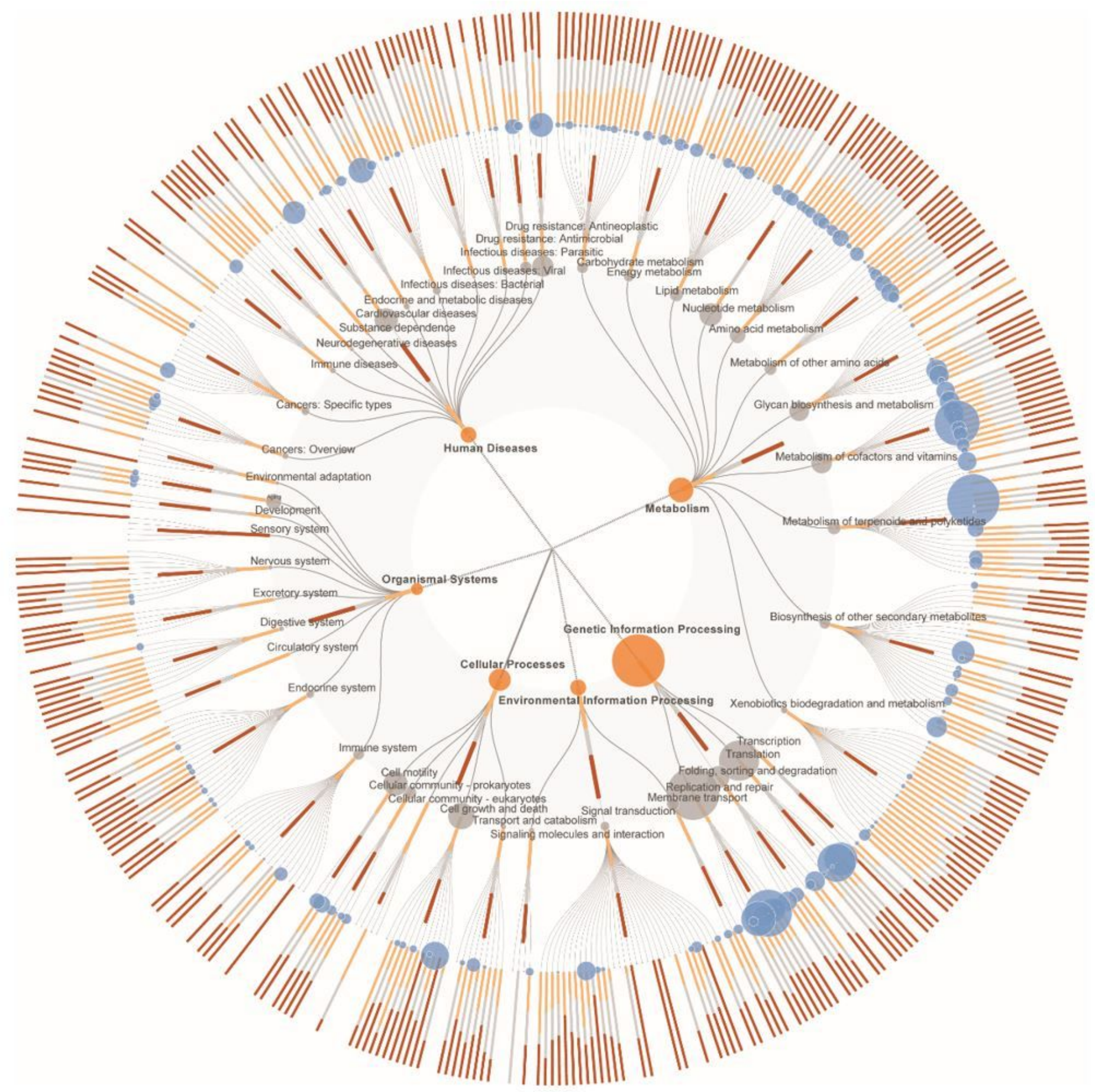

Figure 4

Functional genes from metagenome data enriched using KO terms from Delhi stretch of Yamuna River through KEGG orthologous pathways displaying coloured nodes for biological functions at different level of hierarchy. The KEGG module pathways show all possible broad functional pathways of KEGG in a single map for all the three metagenomics samples (orange: sample 1, grey: sample 2 and red: sample 3 ). The image was generated using the KO terms from KEEG analysis using FuncTree 2 tool. 


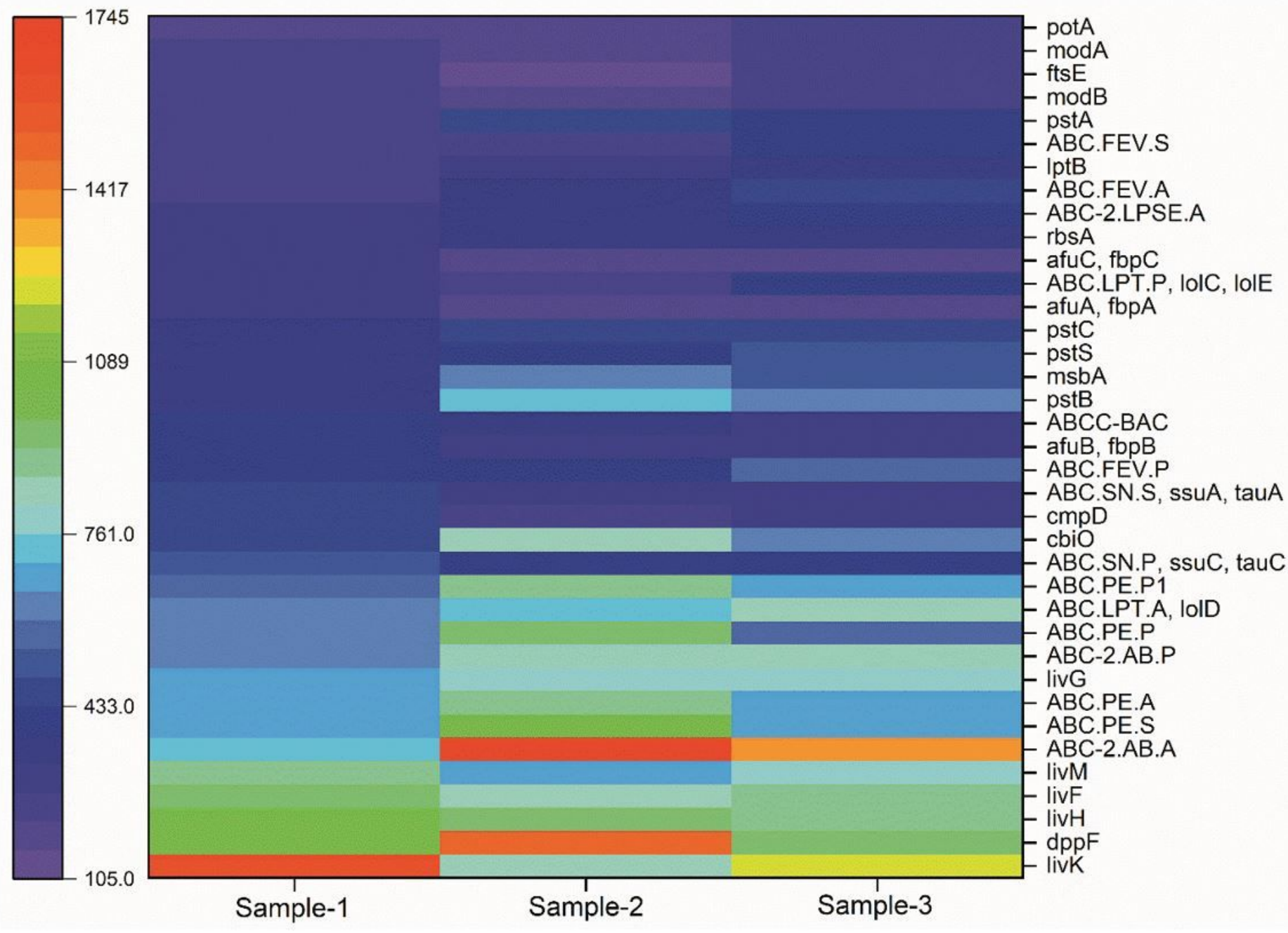

Figure 5

Heatmap showing the abundance of genes under the functional category "ABC transporters" in the sediment metagenomes of river Yamuna. 

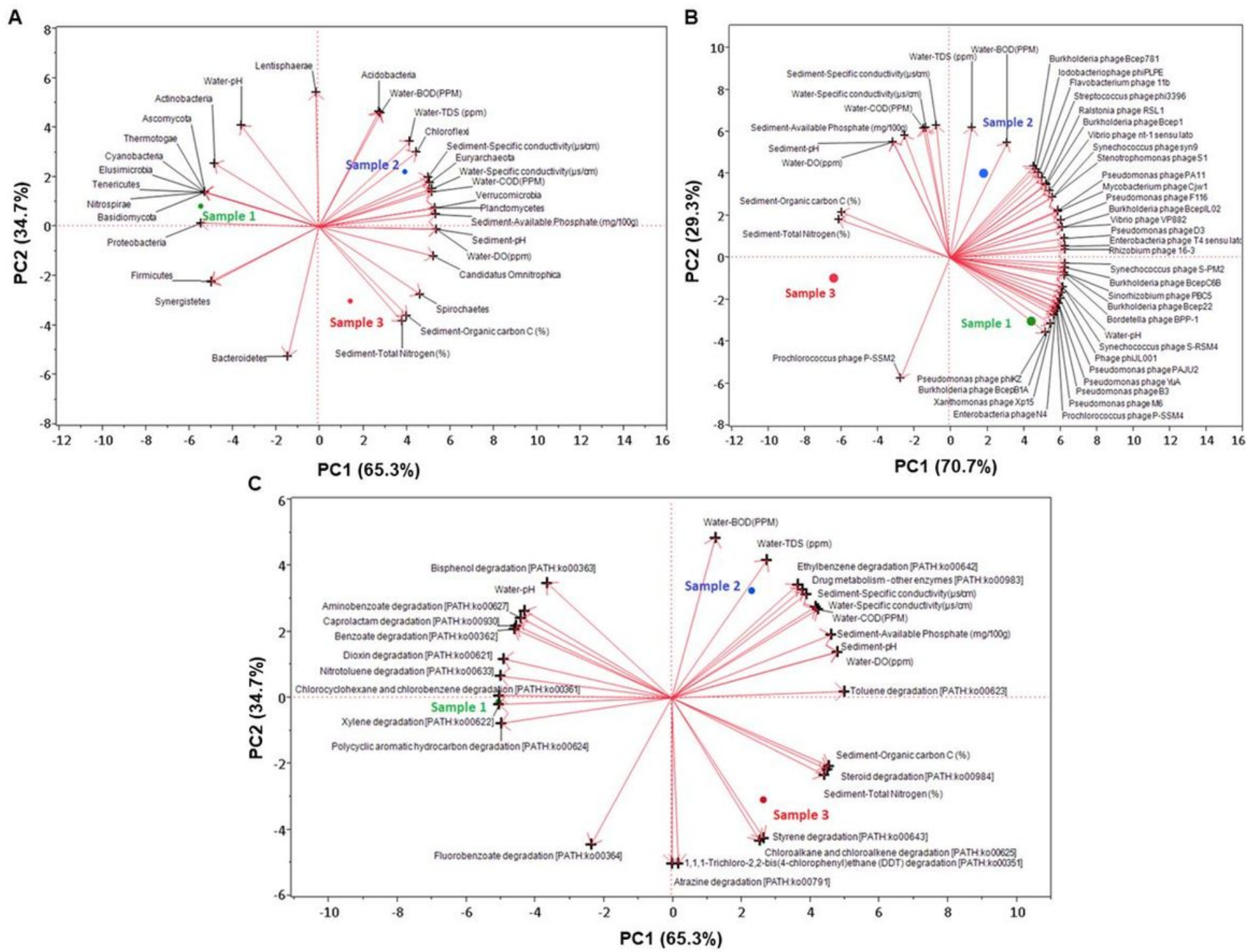

Figure 6

Principal component analysis of the relative abundance of microbiome at phylum level, diversity of bacterial phages and pathways involved in degradation of xenobiotic compounds with water and sediment quality parameters in the three sample of river Yamuna. (A) PCA biplot (PC1 vs. PC2) of the relative abundance at phylum level as compared to water and sediment quality parameters. (B) PCA of the relative abundance of phages as compared to water and sediment quality parameters. (C) PCA of the pathways associated with degradation of xenobiotic compounds with water and sediment quality parameters.

\section{Supplementary Files}

This is a list of supplementary files associated with this preprint. Click to download.

- SupportingInfo.xlsx

- Supportinglnformation.docx 